\title{
Designing Collaboration Processes and Systems
}

\author{
Gert-Jan de Vreede \\ University of Nebraska at Omaha \& \\ Delft University of Technology \\ gdevreede@mail.unomaha.edu
}

\author{
Robert O. Briggs \\ University of Nebraska at Omaha \& \\ Delft University of Technology \\ rbriggs@mail.unomaha.edu
}

\author{
Gwendolyn L. Kolfschoten \\ Delft University of Technology \\ g.l.kolfschoten@tudelft.nl
}

Research shows that, under certain circumstances, groups using collaboration technologies can be far more productive than groups using other means to accomplish their tasks. Furthermore, collaboration appears to be a success critical skill in the new dynamic and innovative knowledge economy. However, experience in the field suggests that organizations do not tend to become selfsustaining in the use of collaboration support until they incorporate it into their daily work practices, in support of mission critical tasks that are guided over and over again by practitioners themselves, rather than facilitated by an outsider facilitator. The challenge for researchers and practitioners alike is to design sustainable processes and systems within and between organizations that allow people to collaborate successfully. The challenge has many dimensions, including a technical, a behavioral, an economical, and a political.

This year's minitrack brings together a diverse set of papers. Out of a total of 24 submissions, 13 were accepted to the proceedings. Together these papers cover a broad range of interesting topics ranging from case studies and pattern research in collaboration to advances in Collaboration Engineering.

The first session offers a number of papers that discuss case studies in Collaboration Engineering: "Collaboration Engineering for Incident Response Planning: Process Development and Validation" by Mehruz Kamal, Alanah Davis, Josephine Nabukenya, Terrance Schoonover, Leah Pietron, and Gert-Jan de Vreede, "How to increase GSS transition? A case study at a Dutch police force" by Marielle den Hengst, Lis Weimar, and Stephan den Hengst, and "Designing and Evaluating Collaborative Processes for Requirements Elicitation and Validation" by Ann Fruhling, Lucas Steinhauser, and Greg Hoff.

The second session hosts several papers on conceptual and theoretical advances in Collaboration Engineering: "A Framework for Studying Voting in Group Support Systems" by Kung-E Cheng and Fadi Deek, "Bounded
Ideation Theory: A New Model of the Relationship Between Idea-quantity and Idea-quality during Ideation" by Robert Briggs and Bruce Reinig, and "Reconceptualizing Generate thinkLets: the Role of the Modifier" by Gwendolyn Kolfschoten and Eric Santanen.

The third session consists of papers addressing patterns and work-practices in collaboration: "An Assessment Framework for Developing and Using Patterns for the Effective Management of Virtual Projects" by Deepak Khazanchi and Ilze Zigurs, "Which collaboration patterns are most challenging: a global survey of facilitators" by Marielle den Hengst and Mark Adkins, and "A Hybrid Approach To Identifying and Visualizing Collaborative Knowledge Work Practices" by Markus Strohmaier, Stefanie Lindstaedt.

The last session consists of papers addressing case studies and experiences in the design of collaboration processes and systems: "Developing Applications and Methodologies for Electronically Facilitated Project Planning: a Coast Guard Case Study"; Lionel Mew, William Money. "Innovating Collaborative Content Creation: The Role of Altruism and Wiki Technology"; Christian Wagner, Pattarawan Mai Prasarnphanich, "Participant-driven GSS: Quality of brainstorming and allocation of participant resources"by Joel Helquist, Eric Santanen, and John Kruse, and "Using GSS Capabilities to Reduce Conflict and Animosity by Reversing Traditional Approaches to Emergent Consensus Building - an Action Research Study”by K. Niki Kunene.

The papers in this minitrack discuss different collaboration technologies and different collaboration processes. Each offers a unique contribution to our understanding of how software tools and methods could be and should be developed and deployed in support of mission critical collaborative tasks. We commend them to your reading, and hope they will inspire your research and practice. 